\title{
COVID-19 in Immunosuppressed and Cancer Patients: A Review
}

\section{Shirin Haghighat ${ }^{1}$, Mehdi Dehghani ${ }^{2}$}

${ }^{1}$ Hematology and Medical Oncology Department, Shiraz University of Medical Science, Shiraz, Iran. ${ }^{2}$ Hematology Research Center, Hematology and Medical Oncology Department, Shiraz University of Medical Science, Shiraz, Iran.

\begin{abstract}
The rapidly spreading outbreak of infection by novel coronavirus 2 (SARS-CoV-2) from Wuhan, China around the world has started since December 2019. Since the epidemic spread of this infection, individuals with comorbidities are at high risk of severe disease and increased rate of mortality. As patients with cancer are considered immunosuppressed caused by some host and treatment factors, a more detailed investigation on the impact of cancer on COVID-19 outcome seems to be necessary. This review article provides data on cancer patients affected by SARS-CoV-2 infection. Although underlying immunosuppression has not proven as a risk factor for severe COVID-19 infection, most authors have identified cancer patients as a highly vulnerable population. We need more detailed especially randomized studies to compare the outcome of cancer and non-cancer patients with SARS-CoV-2 infection. The more precise studies would help oncologists to make the best decision in cancer therapy.
\end{abstract}

Keywords: COVID-19- cancer- immunosuppression

Asian Pac J Cancer Care, 5 (Suppl 1), 69-73

Submission Date: 05/24/2020Ａcceptance Date: 06/28/2020

\section{Introduction}

Several countries from the different continents around the world are experiencing an outbreak of new coronavirus called severe acute respiratory syndrome coronavirus 2 (SARS-CoV-2). In December 2019, coronavirus disease (COVID-19) began in Wuhan, China, and spread rapidly and was reported more than 80,000 confirmed cases with 3000 deaths in China [1]. The two other human coronavirus $(\mathrm{HCoV})$ infection epidemics, severe acute respiratory syndrome coronavirus (SARS-CoV), and Middle East respiratory syndrome coronavirus (MERS$\mathrm{CoV}$ ) were reported first in China and Saudi Arabia in 2003 and 2012 respectively [2]. These HCoVs can present with a wide spectrum of respiratory symptoms ranging from the common cold to acute respiratory distress syndrome [3]. Similarly, the clinical presentation of COVID-19 can be mild (no or mild pneumonia) in $81 \%$ of cases, severe (dyspnea, hypoxia and lung involvement in radiographies) in $14 \%$ cases, and critical (respiratory failure, multiorgan failure or shock) in $5 \%$ of cases [4]. Underlying conditions which have been associated with severe disease and mortality include age more than 65 , hypertension, diabetes mellitus, cardiovascular disease, tumor surgery, cirrhosis, parkinson's disease, obesity, and male sex [5-8]. As the covid-19 outbreak grew, concern has raised about the risk of severe disease and increased fatality among immunosuppressed or cancer patients. Our purpose of this study is to review the vulnerability of patients with cancer to SARS-CoV-19.

The role of immune response in respiratory viral infection Immunopathology of viral infection of the respiratory tract not only is the direct effects of the viral pathogen but also includes the response of the respiratory cells and recruited immune cells of the host [9]. When the mucus layer of the respiratory tract fails as the first line of defence against the viral pathogen, the innate immune system is engaged in eliminating the virus [10]. The innate immune response starts by pattern recognition receptors (PRR) which are sensors for pathogen- or microbe-associated molecular patterns (PAMP/MAMP) [9]. The most

Corresponding Author:

Dr. Shirin Haghighat

Hematology and Medical Oncology Department, Shiraz University of Medical Science, Shiraz, Iran.

Email: sh.haghighat2010@yahoo.com 
important PRRs for recognizing the forms of RNA which are produced by respiratory RNA viruses are Toll-like receptors 3,7 , and 8 [11].

Large variety of pro-inflammatory cytokines and chemokines are produced by respiratory epithelial cells including interferon (IFN), interleukin-6 (IL-6), tumor necrosis-factor alpha (TNF- $\alpha$ ), granulocyte colonystimulating factor (G-CSF), granulocyte-macrophage colony-stimulating factor (GM-CSF), and IL-8 [9]. Type 1 IFN is the crucial cytokine involved in defence against viral pathogen invading the respiratory system [12]. Several antiviral roles of type 1 IFN include stimulating phagocytosis and dendritic cell maturation, significant impact on dendritic cells, and enhancing the activity of lymphocytes [9]. Despite the essential role of IFN in viral pathogen elimination, some adverse action can be induced by IFN such as lymphopenia, tissue injury by expression and release of pro-apoptotic TNF-related apoptosisinducing ligand (TRAIL) [10]. High viral replication in the respiratory tract may be associated with dysregulated host immune response and the production of plenty of pro-inflammatory mediators [13]. Rapid elevation in pro-inflammatory cytokines/chemokines would increase the recruitment of innate and adaptive immune cells to the lung. In addition, release of these mediators can damage the endothelial-epithelial barrier and alveolar epithelium eventually leads the acute respiratory distress syndrome (ARDS) [9][14]. Therefore, exaggerated host immune response may have a significant role in fatality of respiratory viral infection.

Here, an important question is how exactly immunodeficiency impact the outcome of patients with respiratory viral infection. In a systematic review on risk factors of MERS reported by Park et al. immunosuppressed patients were not at increased risk of mortality due to MERS infection [15]. In a report from a large group of patients with SARS in North America, mortality and morbidity were significant especially among patients with diabetes and other comorbid conditions such as COPD, cancer, and cardiac disease. In that study, immunosuppression was not reported as a risk factor of poor outcome except of patients with cancer [16]. In recent outbreak of COVID-19, Lorenzo D'Antiga reported his experience from a main hospital of Lombardy, Italy, and declared no increased risk of severe pulmonary disease and poor outcome among immunosuppressed patients compared to general population [8].

\section{Respiratory viral infection in cancer patients}

Although risk of infection is higher in hematologic malignancies especially during their neutropenic episodes, several factors predispose patients with solid tumors to infection as well. Patients with solid tumors are not generally immunosuppressed, but the factors which damage to the anatomical barriers such as skin and mucosal surface, obstruction, procedures, medical devices or catheters, and cancer treatment (chemotherapy and radiotherapy) would increase the risk of infection in these patients [17]. Respiratory tract is one of the most common site of infection in patients with both hematologic malignancies and solid tumors. The spectrum of pathogens depends on the type of underlying immune deficit associated with malignancy and its treatment. Respiratory viral infection is seen more in patients with impaired cellular immunity including patients who received corticosteroid or chemotherapy containing purine analogues (Fludarbine, Cladribine, or Pentostatine), and recipients of hematopoietic stem cell transplantation (HSCT) on immunosuppressive prophylaxis of graft-versus host disease (GVHD) [18].

Community acquired respiratory viruses (CRV) are common causes of respiratory infection usually lead to common cold in patients without impaired immunity. While, in patients with cancer, pneumonia occurs in $30 \%$ of CRV infections with high mortality rate [19]. Potential causes of respiratory viral infections include paramyxiviridae (parainfluenza,respiratory syncytial virus [RSV], and human metapneumovirus [hMPV]), orthomyxoviridae (influenza A,B,C), coronaviridae, picornaviridae ,adenoviridae, polyomavirus type 1, and bocavirus [20]. Although there is some data regarding the presentation and outcome of some CRV such as influenza and RSV in patients with cancer, information on most of these respiratory viruses in these groups of patients is insufficient [19][21].

\section{Coronaviruses infection in cancer patients}

Coronaviruses are a large family of single-stranded RNA viruses, which were denominated for their corona-like morphology on electron microscopy [22]. CoVs can infect both animals and humans, causing respiratory, enteric, hepatic and central nervous system diseases [22][23]. Gerna et al. have shown that among 823 patients were hospitalized for respiratory infection, 5.7\% were found to be infected by coronavirus. Surprisingly, in that study all infected adults were immunocompromised [24].

Although it is well known that individuals affected by cancer may be more susceptible to severe pulmonary viral infection, cancer and coronavirus infection still has not been well-studied field. Only, there is some small reports in recipients of HSCT who developed severe pulmonary infection. In a case report, Folz et al documented coronavirus infection in a young woman with breast cancer who developed pneumonia following autologous bone marrow transplantation (BMT). They recommended consideration of $\mathrm{CoV}$ in the differential diagnosis of pulmonary symptoms in recipients of high dose chemotherapy and autologous BMT [25]. Another case report published in 2012 was a 38 years old woman who underwent autologous hematopoietic stem cell transplantation for severe systemic lupus erythematous. The patient died 26 weeks after transplantation following treatment as influenza for her presentation of pulmonary infiltration and hypoxia. Finally, HCoV RNA was identified in bronchoalveolar lavage fluid (BAL) at autopsy [26]. Milano et al. reported $11 \%$ the day 100 cumulative incidence of $\mathrm{HCoV}$ infection among recipients of allogeneic hematopoietic stem cell transplantation which was in second place between other viruses after human 
rhinovirus. Despite the high incidence of $\mathrm{HCoV}$ infection among recipients of HSCT, morbidity and mortality was low in their cohort study and none of the patients with coronavirus developed lower respiratory tract infection [27]. Hakki et al. have also found the high incidence of $\mathrm{CoV}$ infection among patients who underwent HSCT, $9.7 \%$ of infection episodes which was in third place after rhinovirus and enterovirus. Similar to Milano et al. study, possible and proven lower respiratory tract infection was lower in coronavirus infection compared to other types of virus [28].

How cancer and chemotherapy impact the COVID-19 outcome?

As the COVID-19 spread rapidly, concern has raised about the patients with cancer and who are on anticancer treatment. These patients might be at significant risk of severe COVID-19 and poor outcome. Data about the impact of two previous coronaviruses infection outbreak (SARS and MERS) is limited. In a Canadian retrospective case series involving 144 patients with SARS, 21-day outcome was described. They reported 8 deaths in their cohort of 144 patients (21-day mortality of $6.5 \%$ ) which one of 8 died patients had cancer [16]. Although in Korean study malignancy was not associated with increased case fatality rate (CFR) in patients with MERS [29], Jazieh et al. have reported increased CFR resulting from MERS-CoV infection among patients with cancer (only 3 patients with early stage cancer from a total 19 patients with cancer survived) [30]. There are significant variations in the predictors of mortality in MERS patients between different studies. Malignancy was reported as one of the risk factors of death in some of these studies [15].

In the recent coronavirus outbreak, COVID-19, many questions about patients with cancer have still remained. Many cancer institutions are confounded about the treatment plan of these group of patients during present pandemic. A prospective cohort on COVID-19 patients in China, 18 of 1590 COVID-19 cases had a history of cancer which was more than the incidence of cancer in general population in China. The most common cancer type was lung cancer. Also, patients with cancer have found to have poorer outcome [31]. The experience from a cancer institute in Italy has been reported by Trapani et al [32]. They identified nine cancer patients diagnosed by COVID-19. Only two of nine patients showed severe pneumonia and none of these patients with severe COVID-19 was receiving immunotherapy, considered as a risk factor for serious COVID-19.

A multicentre study from 14 hospitals in Hubei Province, China, described the clinical characteristics and outcome of 536 COVID-19 cases without cancer and 105 hospitalized COVID-19 patients with cancer [33]. They revealed that patients with cancer had poorer outcome compared to non-cancer patients. In that study, outcome of the COVID-19 was influenced by tumor type, and patients with hematologic malignancies had more aggressive course compared to patients with solid tumors.

Another retrospective cohort study by Zhang and colleagues has represented clinical outcome of 28 cancer patients among 1276 COVID-19 patients admitted in three hospitals in Wuhan. The mortality rate of this patients was $28.6 \%$ which was much higher than fatality rate of COVID-19 in general population of China (2.3\%) [34].

Conversely, some small studies have represented milder symptoms in patients with cancer. for instance, Guan et al. extracted data of 1099 patients infected by $\mathrm{HCoV}-2$ and found only 10 patients with history of cancer $(0.9 \%$ of all patients). Most of these patients had mild symptoms (7 of 10 patients) [35]. Another study represented the severity assessment of 69 patients with COVID-19 by $\mathrm{SpO} 2$. Severe disease $(\mathrm{SpO} 2<90 \%)$ was seen in only 0 ne of 4 cancer patients which was comparable to total cases of study [36].

Although most of these studies are retrospective and nonrandomized and have different results, some of them support the vulnerability of patients with cancer in this coronavirus pandemic. There is great uncertainty in healthcare system involving the cancer patients about the management of cancer during the pandemic. Beside the susceptibility of cancer patients to severe COVID-19, there are some limitation in the management of cancer patients during pandemic as well, including shortage of blood products, involving most staffs in COVID-19 centres, postponing their appointment especially due to travel restriction, and misgiving about the treatment of cancer. Despite all of the mentioned controversies about the outcome of patients affecting by COVID-19, many cancer institutions around the world publish some guidelines in the management of cancer patients during the pandemic. Some important factors involving in the decision about cancer therapy include cancer prognosis, cancer stage, treatment setting (adjuvant, neoadjuvant, or palliative), type of cancer treatment (intravenous versus oral chemotherapy, radiotherapy, or surgery), impact of delay, modify or interrupt the chemotherapy on cancer outcome, probability of COVID-19 infection, and patient comorbidities.

In Conclusion, the issue of cancer and COVID-19 is not yet well studied, including only some small Italian and Chinese series and retrospective studies. Many questions have remained without clear answer. Representing the cancer as a risk factor for severe COVID-19 and poor outcome by authors have raised the concern about the decision about the cancer therapy. Certainly, we need more detailed studies on cancer and COVID-19 to determine the impact of cancer therapy on outcome of COVID-19 and the effects of this pandemic on treatment of cancer.

\section{References}

1. Yang G, Zhang H, Yang Y. Challenges and Countermeasures of Integrative Cancer Therapy in the Epidemic of COVID-19. Integrative Cancer Therapies. 2020 01;19:153473542091281. https://doi.org/10.1177/1534735420912811

2. Yang Y, Peng F, Wang R, Guan K, Jiang T, Xu G, Sun J, Chang C. The deadly coronaviruses: The 2003 SARS pandemic and the 2020 novel coronavirus epidemic in China. Journal of Autoimmunity. 2020 05;109:102434. https://doi. org/10.1016/j.jaut.2020.102434

3. Yin Y, Wunderink RG. MERS, SARS and other coronaviruses 
as causes of pneumonia. Respirology. 2017 Oct 20;23(2):130137. https://doi.org/10.1111/resp.13196

4. McIntosh K. Coronavirus disease 2019 (COVID-19): Epidemiology, virology, clinical features, diagnosis, and prevention . www.uptodate.com $>$ contents $>$ coronavirusdisease-20.

5. Li X, Xu S, Yu M, Wang K, Tao Y, Zhou Y, Shi J, Zhou M, Wu B, Yang Z, Zhang C, Yue J, Zhang Z, Renz H, Liu X, Xie J, Xie M, Zhao J. Risk factors for severity and mortality in adult COVID-19 inpatients in Wuhan. Journal of Allergy and Clinical Immunology. 2020 04; https://doi.org/10.1016/j. jaci.2020.04.006

6. Lai C, Shih T, Ko W, Tang H, Hsueh P. Severe acute respiratory syndrome coronavirus 2 (SARS-CoV-2) and coronavirus disease-2019 (COVID-19): The epidemic and the challenges. International Journal of Antimicrobial Agents. 2020 03;55(3):105924. https://doi.org/10.1016/j. ijantimicag.2020.105924

7. Adhikari SP, Meng S, Wu Y, Mao Y, Ye R, Wang Q, Sun C, Sylvia S, Rozelle S, Raat H, Zhou H. Epidemiology, causes, clinical manifestation and diagnosis, prevention and control of coronavirus disease (COVID-19) during the early outbreak period: a scoping review. Infectious Diseases of Poverty. 202003 17;9(1). https://doi.org/10.1186/s40249020-00646-x

8. D'Antiga L. Coronaviruses and Immunosuppressed Patients: The Facts During the Third Epidemic. Liver Transplantation. 202004 24;26(6):832-834. https://doi.org/10.1002/lt.25756

9. Newton AH, Cardani A, Braciale TJ. The host immune response in respiratory virus infection: balancing virus clearance and immunopathology. Seminars in Immunopathology. 2016 03 10;38(4):471-482. https://doi.org/10.1007/s00281-0160558-0

10. Troy N, Bosco A. Respiratory viral infections and host responses; insights from genomics. Respiratory Research. 2016;17:156.

11. Kikkert M. Innate Immune Evasion by Human Respiratory RNA Viruses. Journal of Innate Immunity. 2019 Oct 14;12(1):4-20. https://doi.org/10.1159/000503030

12. Takeuchi $\mathrm{O}$, Akira $\mathrm{S}$. Innate immunity to virus infection. Immunological Reviews. 2009 01;227(1):75-86. https:// doi.org/10.1111/j.1600-065x.2008.00737.x

13. Gao R, Bhatnagar J, Blau DM, Greer P, Rollin DC, Denison AM, Deleon-Carnes M, Shieh W, Sambhara S, Tumpey TM, Patel M, Liu L, Paddock C, Drew C, Shu Y, Katz JM, Zaki SR. Cytokine and Chemokine Profiles in Lung Tissues from Fatal Cases of 2009 Pandemic Influenza A (H1N1). The American Journal of Pathology. 2013 Oct;183(4):12581268. https://doi.org/10.1016/j.ajpath.2013.06.023

14. Shah RD, Wunderink RG. Viral Pneumonia and Acute Respiratory Distress Syndrome. Clinics in Chest Medicine. 2017 03;38(1):113-125. https://doi.org/10.1016/j. ccm.2016.11.013

15. Park J, Jung S, Kim A. MERS transmission and risk factors: a systematic review. BMC Public Health. 2018;18:574.

16. Booth CM. Clinical Features and Short-term Outcomes of 144 Patients With SARS in the Greater Toronto Area. JAMA. 200306 04;289(21):2801. https://doi.org/10.1001/ jama.289.21.joc 30885

17. Rolston KVI. Infections in Cancer Patients with Solid Tumors: A Review. Infectious Diseases and Therapy. 2017 02 03;6(1):69-83. https://doi.org/10.1007/s40121-0170146-1

18. Rolston KV. The spectrum of pulmonary infections in cancer patients. Current Opinion in Oncology. 2001 07;13(4):218223. https://doi.org/10.1097/00001622-200107000-00002
19. von Lilienfeld-Toal M, Berger A, Christopeit M, Hentrich M, Heussel CP, Kalkreuth J, Klein M, Kochanek M, Penack O, Hauf E, Rieger C, Silling G, Vehreschild M, Weber T, Wolf H, Lehners N, Schalk E, Mayer K. Community acquired respiratory virus infections in cancer patients-Guideline on diagnosis and management by the Infectious Diseases Working Party of the German Society for haematology and Medical Oncology. European Journal of Cancer. 2016 Nov;67:200-212. https://doi.org/10.1016/j.ejca.2016.08.015

20. Hijano DR, Maron G, Hayden RT. Respiratory Viral Infections in Patients With Cancer or Undergoing Hematopoietic Cell Transplant. Frontiers in Microbiology. 2018 Dec 12;9. https://doi.org/10.3389/fmicb.2018.03097

21. Arjeyni Y, Goudarzi H, Eslami G, Faghihloo E. Viral Respiratory Infections in Patients with Cancer. Iranian Journal of Cancer Prevention. 201702 15; In Press(In Press). https://doi.org/10.5812/ijcp.8084

22. Weiss SR, Navas-Martin S. Coronavirus Pathogenesis and the Emerging Pathogen Severe Acute Respiratory Syndrome Coronavirus. Microbiology and Molecular Biology Reviews. 2005 Dec;69(4):635-664. https://doi.org/10.1128/ mmbr.69.4.635-664.2005

23. Weiss S, Leibowitz J. Coronavirus Pathogenesis . Adv Virus Res. 2011;81:85-164.

24. Gerna G, Campanini G, Rovida F, Percivalle E, Sarasini A, Marchi A, Baldanti F. Genetic variability of human coronavirus OC43-, 229E-, and NL63-like strains and their association with lower respiratory tract infections of hospitalized infants and immunocompromised patients. Journal of Medical Virology. 2006;78(7):938-949. https:// doi.org/10.1002/jmv.20645

25. Folz RJ, Elkordy MA. Coronavirus Pneumonia Following Autologous Bone Marrow Transplantation for Breast Cancer. Chest. 1999 03;115(3):901-905. https://doi. org/10.1378/chest.115.3.901

26. Uhlenhaut C, Cohen J, Pavletic S, Illei G, Gea-Banacloche J, Abu-Asab M, Krogmann T, Gubareva L, McClenahan S, Krause $\mathrm{P}$. Use of a novel virus detection assay to identify coronavirus HKU1 in the lungs of a hematopoietic stem cell transplant recipient with fatal pneumonia. Transplant Infectious Disease. 201107 12;14(1):79-85. https://doi. org/10.1111/j.1399-3062.2011.00657.x

27. Milano F, Campbell AP, Guthrie KA, Kuypers J, Englund JA, Corey L, Boeckh M. Human rhinovirus and coronavirus detection among allogeneic hematopoietic stem cell transplantation recipients. Blood. 201003 11;115(10):20882094. https://doi.org/10.1182/blood-2009-09-244152

28. Hakki M, Rattray RM, Press RD. The clinical impact of coronavirus infection in patients with hematologic malignancies and hematopoietic stem cell transplant recipients. Journal of Clinical Virology. 2015 07;68:1-5. https://doi.org/10.1016/j.jcv.2015.04.012

29. Nam H, Park JW, Ki M, Yeon M, Kim J, Kim SW. High fatality rates and associated factors in two hospital outbreaks of MERS in Daejeon, the Republic of Korea. International Journal of Infectious Diseases. 2017 05;58:37-42. https:// doi.org/10.1016/j.ijid.2017.02.008

30. Jazieh A, Alenazi TH, Alhejazi A, Al Safi F, Al Olayan A. Outcome of Oncology Patients Infected With Coronavirus. JCO Global Oncology. 2020 03;(6):471-475. https://doi. org/10.1200/go.20.00064

31. Liang W, Guan W, Chen R, Wang W, Li J, Xu K, Li C, Ai Q, Lu W, Liang H, Li S, He J. Cancer patients in SARSCoV-2 infection: a nationwide analysis in China. The Lancet Oncology. 2020 03;21(3):335-337. https://doi.org/10.1016/ s1470-2045(20)30096-6 
32. Trapani D, Marra A, Curigliano G. The experience on coronavirus disease 2019 and cancer from an oncology hub institution in Milan, Lombardy Region. European Journal of Cancer. 2020 06;132:199-206. https://doi.org/10.1016/j. ejca.2020.04.017

33. Dai M, Liu D, Liu M, Zhou F, Li G, Chen Z, et al. Patients with cancer appear more vulnerable to SARS-COV-2: a multi-center study during the COVID-19 outbreak. Cancer Discov. 2020; https://doi.org/10.1158/2159-8290

34. Zhang L, Zhu F, Xie L, Wang C, Wang J, Chen R, Jia P, Guan H, Peng L, Chen Y, Peng P, Zhang P, Chu Q, Shen Q, Wang Y, Xu S, Zhao J, Zhou M. Clinical characteristics of COVID19-infected cancer patients: a retrospective case study in three hospitals within Wuhan, China. Annals of Oncology. 2020 03; . https://doi.org/10.1016/j.annonc.2020.03.296

35. Guan W, Ni Z, Hu Y, Liang W, Ou C, He J, Liu L, Shan H, Lei C, Hui DS, Du B, Li L, Zeng G, Yuen K, Chen R, Tang C, Wang T, Chen P, Xiang J, Li S, Wang J, Liang Z, Peng Y, Wei L, Liu Y, Hu Y, Peng P, Wang J, Liu J, Chen Z, Li G, Zheng Z, Qiu S, Luo J, Ye C, Zhu S, Zhong N. Clinical Characteristics of Coronavirus Disease 2019 in China. New England Journal of Medicine. 202004 30;382(18):17081720. https://doi.org/10.1056/nejmoa2002032

36. Wang Z, Yang B, Li Q, Wen L, Zhang R. Clinical Features of 69 Cases With Coronavirus Disease 2019 in Wuhan, China. Clinical Infectious Diseases. 202003 16; https:// doi.org/10.1093/cid/ciaa272

\section{c) (i) (8)}

This work is licensed under a Creative Commons AttributionNon Commercial 4.0 International License. 